\title{
MINIREVIEW
}

\author{
Innate Sensing of Viruses by Toll-Like Receptors \\ Karl W. Boehme and Teresa Compton* \\ McArdle Laboratory for Cancer Research, University of Wisconsin-Madison \\ Medical School, Madison, Wisconsin 53706
}

The ability to detect pathogens is arguably the single most important task undertaken by the immune system. Appropriate recognition of invasive microbes is critical for mounting an immune response that can effectively combat the invading organism. A comprehensive understanding of the requirements for pathogen recognition is necessary for the development of efficacious vaccines and effective therapeutics. Toward this end, a tremendous investment has been made in determining how the adaptive immune system ( $\mathrm{B}$ and $\mathrm{T}$ cells) distinguishes invading pathogens from host cells and tissues. These efforts have yielded remarkable models that describe how the immune system responds to the myriad of challenges it faces and provide a framework into which future discoveries can be incorporated. Recently, however, some of this focus has been redirected to understanding how pathogens are initially recognized by the host innate immune system and how these events contribute to and coordinate with the adaptive immune response.

Detection of pathogens by the innate immune system is carried out by a class of immune-sensor molecules termed pattern recognition receptors, or PRRs. Several different classes of PRRs have been identified, each detecting microbes or microbial components and initiating responses that program antipathogen gene expression profiles and promote adaptive immune responses (28). The Toll-like receptors (TLRs) are a class of PRRs that detect an increasingly broad range of pathogens (74). While the majority of the work on TLRs has focused on detection of bacteria, it is becoming increasingly apparent that viruses are also subject to innate sensing by TLRs. An indicator of the importance of any host antiviral strategy is the ability of viruses to counteract that particular arm of the host defense. Two vaccinia virus genes, A46R and A52R, have been implicated as negative regulators of TLR signaling, indicating that TLR responses pose a realistic threat to viruses (11a, 29a). This review will focus on the state of our knowledge of TLRs' role in immune responses to viruses.

\section{TLR STRUCTURE AND SIGNALING}

The TLRs are a series of germ line-encoded molecules that were initially identified based on homology with the Toll receptor from Drosophila $(58,67)$. Drosophila Toll is essential for dorsoventral patterning during fly embryogenesis (72) and was

\footnotetext{
* Corresponding author. Mailing address: McArdle Laboratory for Cancer Research, University of Wisconsin Medical School, Madison, WI 53706. Phone: (608) 262-1474. Fax: (608) 262-2824. E-mail: tcompton@wisc.edu.
}

more recently recognized as a critical component of the fly immune response to fungal pathogens (52). Each member of the TLR family has similar structural characteristics. TLRs are type 1 transmembrane proteins with a single membrane-spanning domain. Their ectodomains are composed of various numbers of leucine-rich repeats (LRRs) which are hypothesized to directly interact with microbes or microbial components. The cytoplasmic tail of TLRs consists of a conserved domain similar to the intracellular region of Drosophila Toll and the interleukin 1 receptor (IL-1R). The Toll/IL-1R (TIR) domain is responsible for initiating intracellular signals.

To date, 11 TLRs have been identified in humans (12 have been identified in mice), and they are expressed predominantly on cell types that are likely to be the first to encounter antigen (17, 18, 23, 58, 67, 75, 82). Phagocytic cells such as macrophages, neutrophils, and dendritic cells exhibit the broadest repertoire and express the highest levels of TLRs $(39,81)$; however, TLR expression is not restricted to these cell types. Although TLR expression patterns and levels in most cell and tissue types are still being defined, it appears that the majority of cells in the body express at least a subset of TLRs. TLRs are predominantly expressed on the cell surface; however, a subset (TLR7, TLR8, TLR9, and in some cases TLR3) are retained in intracellular compartments. The cellular location of TLRs combined with their tissue expression patterns appropriately positions them to interact with pathogens that are encountered by the host.

A significant portion of TLR biology has been elucidated by studying TLR4, the receptor for bacterial lipopolysaccharide (LPS). LPS was initially shown to interact directly with two proteins, the LPS binding protein (LBP) and CD14 $(69,76)$. LBP is a serum protein that binds directly to LPS and mediates its transfer to CD14, which exists either in a soluble form or as a glycosylphosphatidylinositol (GPI)-linked protein (31). Because both of these proteins lack a cytoplasmic component through which signaling responses can be initiated, it was hypothesized that these molecules required the assistance of an additional receptor. The missing component of the LPS recognition complex was identified when analysis of LPS hyporesponsive $\mathrm{C} 3 \mathrm{H} / \mathrm{HeJ}$ and $\mathrm{C} 57 \mathrm{BL} / 10 \mathrm{ScCr}$ mouse strains revealed mutations in the Tlr4 gene $(64,65)$. Subsequently, studies of these mice have been instrumental in examining the role of TLR4 responses in vivo for a variety of pathogens, including viruses.

The primary consequences of TLR activation are NF- $\mathrm{B}$ activation, cytokine secretion (Fig. 1), and expression of costimulatory molecules, such as the class II major histocompat- 


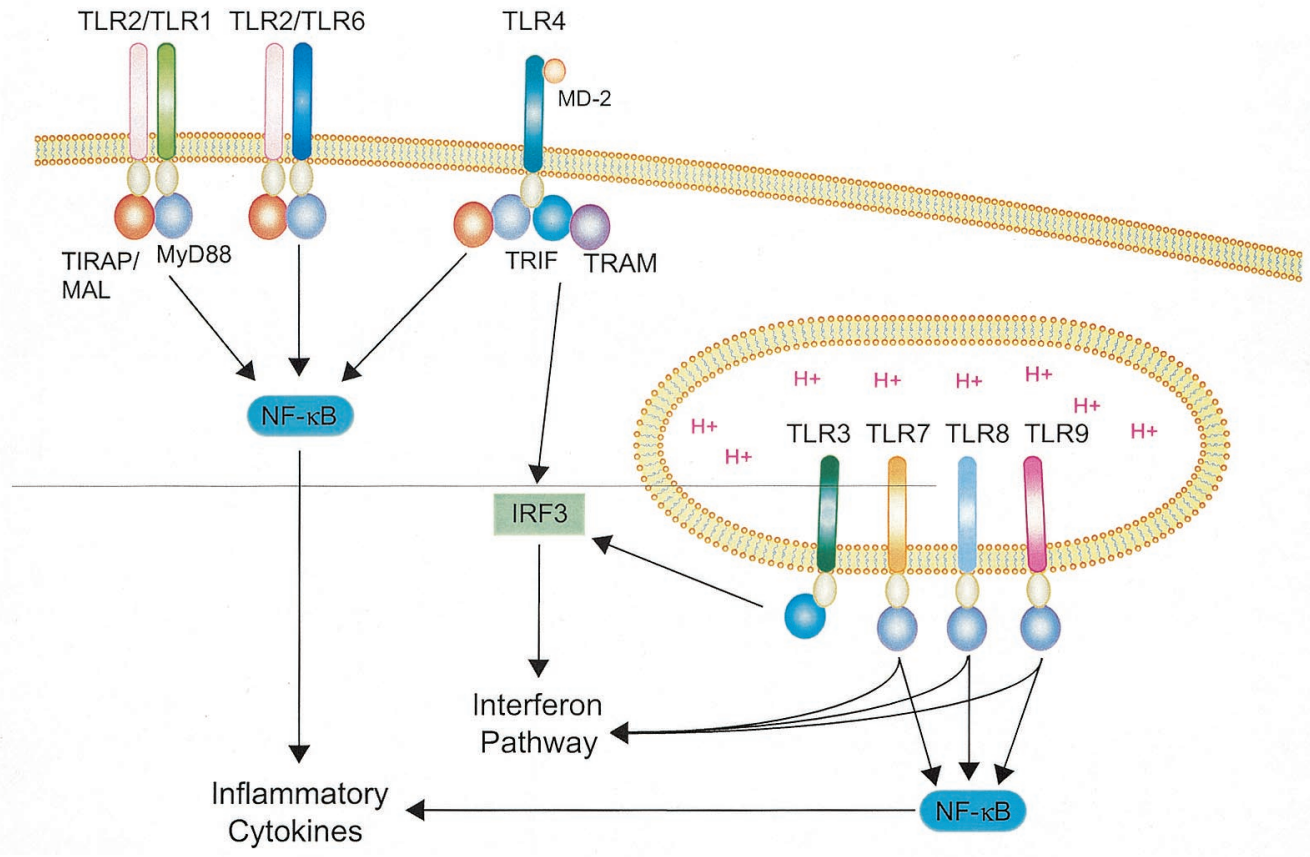

FIG. 1. Schematic of TLR signaling pathways. TLR2 (in combination with TLR1 or TLR6) and TLR4 utilize MyD88 and TIRAP/MAL as primary adaptors to activate NF-кB and inflammatory cytokine secretion. Also, TLR4 uses TRIF and the TRIF-related adaptor molecule (TRAM) to activate IRF3 and the IFN pathway. TLRs 3, 7, 8, and 9 typically localize to endocytic compartments, where they detect a variety of nucleic acids and activate the IFN pathway. TLR3 utilizes TRIF, but not TRAM, to activate IRF3. TLRs 7, 8, and 9 trigger inflammatory cytokine secretion and the IFN pathway through MyD88. Other than MyD88, the signaling intermediates utilized by TLRs 7, 8, and 9 to activate IFN responses remain undefined.

ibility complex and CD86 (74). Together, these responses help promote and shape the critical immunological processes that facilitate pathogen control and clearance. TLR responses are initiated by ligand-induced multimerization, and receptor clustering leads to the recruitment of different combinations of primary adaptor molecules, depending upon the TLR involved (Fig. 1). The majority of the adaptor molecules identified to date contain a TIR domain $(1,10,13,25,38,46,53,61,62,78$, 79). Consequently, TLR-adaptor interactions are mediated by homotypic associations between TIR domains on the receptor and the adaptor. The ability to utilize different combinations of adaptors allows several different signaling pathways to be initiated. The core TLR signaling pathway utilizes myeloid differentiation factor 88 (MyD88) as the primary adaptor and results in $\mathrm{NF}-\kappa \mathrm{B}$ and mitogen-activated protein kinase (MAPK) activation and secretion of a core panel of cytokines (3). Although most TLRs utilize the MyD88-dependent pathway, a subset of TLR responses remains intact in mice with a targeted deletion of the MyD88 gene (43-47), which indicates that additional signaling pathways are activated by TLRs and result in these responses. The MyD88-independent pathway actually encompasses a number of different signaling networks that employ a variety of primary adaptors in combination with, or independent of, MyD88. The activity of these pathways leads to dendritic cell maturation, expression of costimulatory molecules, and alpha/beta interferon (IFN- $\alpha / \beta)$ secretion $(26$, 44, 45, 77-79). The MyD88-independent pathways also present a mechanism by which the TLR system may tailor distinct responses for different types of pathogens. The use of different adaptors by individual TLRs allows for unique responses for a given receptor. Since a comprehensive panel of adaptors used by each TLR has not been defined, a detailed map of the intracellular signaling response initiated by TLRs has yet to be charted.

In addition to the MyD88-dependent and -independent pathways, TLRs interact with a number of additional cellsignaling networks. Both TLR2 and TLR4 induce phosphatidylinositol (PI) 3-kinase activity $(6,59)$, and TLR2 and TLR3 have been linked to the apoptotic pathway $(5,40)$. It is not yet known how these additional networks coordinate with the MyD88-dependent and -independent pathways described above. A comprehensive discussion of TLR signaling is beyond the scope of this report; however, a number of excellent reviews are available concerning different aspects of TLR signaling and adaptor usage $(3,36,60,74)$.

\section{MOLECULAR BASIS OF TLR ACTIVATION}

Similar to the adaptive immune system, the innate immune system possesses the ability to distinguish foreign structures from those of the host organism. TLRs detect pathogens on the basis of motifs termed pathogen-associated molecular patterns (PAMPs) displayed on the invading organism. Bacterial products such as LPS (TLR4), peptidoglycan (TLR2), and deoxycytidylate phosphate deoxyguanylate (CpG) DNA (TLR9) are examples of structures that are subject to recognition by TLRs. With respect to viruses, four classes of PAMPs have emerged to date: double-stranded RNA (dsRNA), CpG 
TABLE 1. Viruses detected by Toll-like receptors

\begin{tabular}{|c|c|}
\hline Toll-like receptor & Virus (molecular target if known) \\
\hline 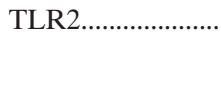 & $\begin{array}{l}. . \mathrm{MV}^{a} \text { (hemagglutinin) } \\
\mathrm{HCMV}^{b} \\
\mathrm{HSV}^{-1}{ }^{c}\end{array}$ \\
\hline TLR3 ........................ &.. $\mathrm{MCMV}^{d}$ \\
\hline TLR4 ....................... & $\begin{array}{l}. . \mathrm{RSV}^{e}(\mathrm{~F} \text { protein }) \\
\text { MMTV }^{f} \text { (envelope protein) }\end{array}$ \\
\hline TLR7 and TLR8 & $\begin{array}{l}. . \text { Influenza A virus (genomic RNA) } \\
\text { HIV- }^{g} \text { (synthetic RNA oligonucleotide } \\
\text { from U5 region of genome) } \\
\text { VSV }^{h}\end{array}$ \\
\hline TLR9 ...................... & $\begin{array}{l}. . H S V-1 \\
\text { HSV-2 (genomic DNA) } \\
\text { MCMV }\end{array}$ \\
\hline
\end{tabular}

\footnotetext{
${ }^{a}$ Measles virus.

${ }^{b}$ Human cytomegalovirus.

${ }^{c}$ Herpes simplex virus type 1 .

${ }^{d}$ Murine cytomegalovirus.

${ }^{e}$ Respiratory syncytial virus.

${ }^{f}$ Mouse mammary tumor virus.

${ }^{g}$ Human immunodeficiency virus type 1 .

${ }^{h}$ Vesicular stomatitis virus.
}

DNA, single-stranded RNA (ssRNA), and envelope glycoproteins. This list is likely to expand as more viruses are demonstrated to activate TLRs. Each of these will be discussed in greater detail below. A list of viruses detected by TLRs is presented in Table 1.

Recognition of dsRNA. It is now well appreciated from the work of numerous laboratories that dsRNA, along with its synthetic analog, polyinosine-poly(C) (poly I:C), is a potent inducer of IFN responses. It was recently demonstrated that TLR3 is a cellular receptor that recognizes dsRNA and initiates these responses (4). dsRNA is a replication intermediate for RNA viruses, and lysis of virus-infected cells is hypothesized to release dsRNA that can be detected by TLR3 molecules expressed on neighboring cells. Interestingly, cells such as fibroblasts express TLR3 on the cell surface; however, in certain dendritic cells, TLR3 expression is restricted to intracellular compartments $(56,57)$. Activation of TLR3 and the subsequent secretion of IFN- $\alpha / \beta$ help to establish a localized antiviral state that limits viral replication at the site of infection.

TLR3-mediated responses are unique among TLR family members because activation of TLR3 elicits lower levels of inflammatory cytokines than other TLRs. However, TLR3 activation induces very robust secretion of IFN- $\beta$ as well as expression of costimulatory molecules (4). Each of these activities is retained in MyD88 ${ }^{-1-}$ mice, suggesting that TLR3 does not require the MyD88-dependent pathway (37). Recent studies have revealed that TLR3 signals through a unique adaptor molecule, TIR domain-containing adaptor-inducing IFN- $\beta$ (TRIF), also known as TIR-containing adaptor molecule-1 (TICAM-1), in place of MyD88 (Fig. 1) (61, 77). Through TRIF/TICAM-1, TLR3 activates NF-кB and IFN regulatory factor 3 (IRF3), a key regulatory transcription factor for cellular antiviral responses, including IFN- $\beta$ secretion. The molecular basis for the TRIF/TICAM-1 preference exhib- ited by TLR3 is likely due to the presence of an alanine residue within a key region of the cytoplasmic domain of TLR3. All other TLRs contain a proline residue at this position and utilize MyD88.

Recognition of CpG DNA. TLR9 was originally identified as the receptor for unmethylated bacterial CpG DNA $(8,35)$. Recently, herpes simplex virus type 1 (HSV-1), HSV-2, and murine cytomegalovirus (MCMV), all of which contain genomes rich in CpG DNA motifs, were shown to activate inflammatory cytokine and IFN- $\alpha$ secretion via TLR9 (48, 54, 73). An important aspect of TLR9 biology is that its activation is inhibited by the addition of chloroquine, which prevents acidification of endosomes $(2,29)$. The current model of TLR9 activation is that in which virus particles are taken up by cells and subsequently degraded within endocytic vesicles, exposing the viral genome which can activate TLR9 (Fig. 1). Intriguingly, TLR9-mediated IFN- $\alpha$ secretion in response to HSV-1, HSV-2, and MCMV occurs in a MyD88-dependent manner $(48,54,73)$, which is in direct contrast to IFN responses mediated by other TLRs, which induce IFN- $\alpha / \beta$ secretion through MyD88-independent pathways. Furthermore, the TLR9-mediated IFN- $\alpha$ response to HSV-1 and HSV-2 may be limited to plasmacytoid dendritic cells (pDCs), a dendritic cell subpopulation characterized by their ability to secrete high levels of IFN in response to viral infection $(7,15,20,21,24,27,63,68$, 70). Murine dendritic cell subsets distinct from pDCs do not secrete IFN- $\alpha$ in response to HSV-1 or HSV-2, indicating that this cell type may be specifically designed to combat viruses $(48,54)$.

Recognition of ssRNA. Imidazoquinolines and specific guanine nucleoside analogs are potent antiviral compounds that activate TLR7 and TLR8 $(32,34,42,51)$. Recently, the PAMP for TLR7 and TLR8 was identified as ssRNA. Like TLR9, TLR7 and TLR8 require endosome acidification for proper activity and induce IFN- $\alpha$ production in a MyD88-dependent manner. Thus, these three TLRs utilize similar mechanisms of action to recognize and respond to distinct nucleic acid targets $(22,32)$. Indeed, TLR7, TLR8, and TLR9 are believed to have evolved from one another, and these similarities support the hypothesis that they comprise a distinct TLR subfamily (18, 23). Influenza A virus, vesicular stomatitis virus (VSV), and human immunodeficiency virus type 1 (HIV) have recently been implicated as subjects of TLR7 surveillance $(22,33,55)$. Purified influenza virus genomic RNA elicits IFN- $\alpha$ from wildtype but not from TLR7 ${ }^{-1-}$ mouse dendritic cells (22). GUrich synthetic oligonucleotides derived from the U5 region of HIV-1 RNA stimulate costimulatory molecule expression as well as inflammatory cytokine and IFN- $\alpha$ secretion in a TLR7dependent manner (33). Furthermore, poly(U) but not $\operatorname{poly}(\mathrm{A}), \operatorname{poly}(\mathrm{C}), \operatorname{poly}(\mathrm{G})$, or $\operatorname{poly}(\mathrm{I})$ compounds activate TLR7. Together, these data suggest that a simple RNA motif is recognized by TLR7 and also raise the question of how cells distinguish between viral and self RNAs (22). These groups suggest that self RNAs are subject to degradation by extracellular RNases. Thus, RNAs taken up by phagocytic cells within the confines of a virus particle are able to activate TLR7, whereas self RNAs rarely reach the endocytic compartment where TLR7 resides. The studies described above utilized mice lacking TLR7; however, genetic complementation experiments with human TLR7 and TLR8 suggest that TLR8, not TLR7, is 
responsible for the recognition of ssRNA in humans (33). These authors point out that murine TLR7 expression does not confer ssRNA responsiveness in their system and may represent a limitation of their experimental approach, leaving open the possibility that TLR7 may function in humans in vivo. However, these data do suggest that TLR7 and TLR8 mediate a species-specific recognition of ssRNA.

Recognition of envelope glycoproteins. Viral envelope glycoproteins are another broad class of molecules that are emerging as the subject of TLR detection. One common theme among the viral glycoproteins implicated to date is that they play critical roles in the binding and/or entry of their respective viruses. Thus, viral pathogens can be detected at the earliest stages of infection simply via contact between glycoproteins on the viral envelope and TLRs on the cell surface, rather than requiring viral gene expression and/or replication.

Respiratory syncytial virus (RSV) was the first virus demonstrated to activate a member of the TLR family, eliciting $\mathrm{NF}-\kappa \mathrm{B}$ activation and inflammatory cytokine secretion in a TLR4- and CD14-dependent manner (50). (Although CD14 was initially identified as an LPS receptor, it is now generally viewed as an enhancer of TLR responses; however, the precise role that CD14 plays in promoting TLR responses is not well understood [50].) The fusion (F) protein from RSV was identified as a viral component that activates TLR4. This observation is consistent with the notion that viral entry, gene expression, and replication may not be required for induction of innate immunity in response to RSV. Furthermore, the importance of TLR4 activation during RSV infection in vivo was demonstrated with mice lacking TLR4 (30). TLR4-deficient mice exhibited lower levels of infiltrating natural killer and $\mathrm{CD}_{14}{ }^{+}$cells and reduced levels of IL-12 in serum than their wild-type counterparts. The physiological consequence of these shortfalls was a reduction in the rate of viral clearance. Taken together, these studies established that viruses were subject to the same form of innate sensing as bacterial and fungal pathogens and that TLR activation by viruses in vivo is a critical aspect of the overall immune response to viral pathogens.

Mouse mammary tumor virus (MMTV) was also shown to activate TLR4 (66). As was the case for RSV, the viral envelope protein (Env) was shown to be the viral component responsible for TLR4 activation (66). J. C. Rassa et al. showed that MMTV Env coimmunoprecipitates with TLR4, providing the first evidence for a physical interaction between a TLR and a viral glycoprotein. Furthermore, the physical interaction between TLR4 and MMTV Env appears to occur via a proteinprotein interaction, since both can be coimmunoprecipitated in the presence of tunicamycin (66). These authors speculate that TLR4 activation by Env may have a positive effect on viral replication by directly activating $\mathrm{B}$ cells, allowing an initial round of viral replication or feedback of TLR4-induced cytokines, which may promote provirus transcription. A recent study has revealed that MMTV activation of TLR4 on dendritic cells enhances expression of its entry receptor, CD71 (14), which suggests that activation of TLR4 by MMTV facilitates viral entry in addition to the replication-enhancing effects described above. This report also showed that TLR2 is activated by MMTV and that TLR2 responses may contribute to these processes (14).
Further evidence for a relationship between TLR4 and MMTV is demonstrated by the observation that wild-type MMTV is retained in mice expressing functional TLR4 $(\mathrm{C} 3 \mathrm{H} /$ $\mathrm{HeN})$, but in mice expressing a nonfunctional TLR4 $(\mathrm{C} 3 \mathrm{H} /$ $\mathrm{HeJ}$ ), wild-type MMTV is replaced with a recombinant of MMTV and the endogenous provirus (Mtv) (41). Secretion of the immunosuppressive cytokine IL-10 by B cells is responsible for inhibiting the antiviral response to MMTV and preserves wild-type MMTV in TLR4-expressing mice. However, B-cell production of IL-10 is not a direct consequence of TLR4 activation; rather, an unidentified TLR4-dependent signal from dendritic cells and macrophages prompts B cells to secrete IL-10.

Measles virus (MV), through its hemagglutinin protein, induces NF-кB and inflammatory cytokine secretion via TLR2 (9). In contrast to the wild-type virus, tissue culture-adapted vaccine strains were not able to stimulate TLR2. This observation is intriguing because one would predict that an efficacious vaccine would be more likely to trigger innate immune responses than virulent wild-type strains. The resolution to this apparent contradiction may lie in the observation that the receptor for wild-type MV, CD150, is up-regulated in human monocytes upon TLR2 activation. Vaccine MV strains, in contrast, utilize CD46 as an entry receptor (9).

Recently, our laboratory demonstrated that human CMV is able to activate and signal through TLR2 (19). NF-кB is activated and inflammatory cytokine secretion is induced in a TLR2-dependent manner in response to CMV. Furthermore, similar to most TLR2-mediated responses, the response to CMV is enhanced by the presence of CD14. The observation that dense bodies (fusion-competent defective particles lacking capsid and viral DNA but rich in envelope and tegument proteins) trigger responses identical to those of live and UVinactivated virions initially suggested that CMV is in the group of viruses that trigger TLR activation during virus-cell contact and/or entry. In contrast to paramyxoviruses and retroviruses, CMV is extremely structurally complex, displaying at least 12 envelope glycoproteins. Soluble forms of envelope glycoprotein $\mathrm{B}(\mathrm{gB})$ activate NF- $\mathrm{B}(80)$ and IRF3, induce IFN- $\beta$ secretion, and render an antiviral state in cells $(11,12,16,71)$. More recently, we have found that soluble $\mathrm{gB}$ also induces inflammatory cytokine secretion in a TLR2-dependent manner. Furthermore, a direct interaction between $\mathrm{gB}$ and at least one other CMV envelope protein with TLR2 was found, suggesting that multiple glycoproteins from a single virus can display recognition motifs (M. Guerrero and T. Compton, unpublished data). At this point, it is unclear whether induction of antiviral responses to CMV is a TLR2-mediated process, and to date no link has been established between TLR2 and activation of the IFN pathway.

HSV-1 is another herpesvirus that may activate TLRs via one of its envelope glycoproteins. Like CMV, HSV-1 elicits inflammatory cytokine secretion through TLR2; however, the viral trigger has yet to be defined. HSV-1 has an intimate relationship with the host immune system, and immunomodulation by TLR2 activation appears to play a prominent role in HSV-1-associated immunopathology (49). Challenge of adult $\mathrm{TLR}^{-1-}$ mice with lethal doses of HSV-1 (KOS strain) resulted in lower levels of IL-6 in serum and decreased levels of monocyte chemotactic protein 1 in the brain compared to 
those of the control mice. Interestingly, virus dissemination was similar in wild-type and TLR2-null mice, but TLR2 $2^{-1-}$ mice were significantly more resistant to lethal HSV-1 challenge than wild-type mice. This trend was also observed in neonatal mice. Consistent with the decreases in cytokine levels, infiltration of mononuclear cells was lower in TLR2 ${ }^{-1-}$ mice. These results suggest that TLR2-mediated cytokine responses to HSV-1 are responsible for a significant portion of the morbidity and mortality associated with HSV-1 infection. As described above, HSV-1 also activates TLR9 (49). Activation of multiple TLRs by a single pathogen may be advantageous to the host, as it would allow the immune system to more precisely identify an invading pathogen and then mount an appropriate response. Experiments comparing double- and singleknockout mice may provide exciting new insights into how activation of multiple TLRs by a single pathogen is coordinated.

The ability of glycoproteins to stimulate TLRs is intriguing because they are synthesized within host cells and therefore do not intuitively harbor modifications or moieties that differ significantly from those of the host. It is possible that these proteins possess unique structural conformations and/or clusters of glycans that host proteins do not assume. It seems highly likely that some underlying common pattern is displayed that is particular to the glycoproteins of viruses. Future work will undoubtedly be aimed at defining the molecular basis of PAMPs on viral envelope glycoproteins.

\section{FUTURE CONSIDERATIONS}

We have only begun to delve into the roles of TLR pattern recognition receptors in virus infections and host immunity. A number of important questions await further investigation. One central question has to do with the ability of the TLR machinery to broadly recognize viruses. To date, only enveloped viruses have been found to be subject to innate immune surveillance by TLRs. It will be of interest to determine if pathogen recognition by TLRs extends among other enveloped viruses and nonenveloped viruses. Dissection of the molecular basis of virally displayed PAMPs is also fundamental to understanding the molecular basis of TLR recognition of viruses. In the instances of TLR activation in concert with virus entry, we need to further investigate how entry events such as binding and fusion are coordinated with innate sensing. Do viral entry receptors and their associated interactions with envelope glycoproteins contribute to or augment TLR activation? How does TLR activation modulate and promote host immunity, and what is the relationship of pathogenicity, virulence, and TLR responses to viruses? How do TLR responses influence the processes of persistence and latency? The answers to these questions will shed light on the delicate balance between pathogen and host and may lead to improved, more efficacious viral vaccines.

\section{ACKNOWLEDGMENTS}

We acknowledge numerous contributions from many laboratories whose references we were unable to cite because of space limitations. Members of the Compton laboratory are gratefully acknowledged for critical readings of the manuscript.

The work discussed in this review from our laboratory is supported by NIH grants RO1 AI34998 and RO1 A154915.

\section{REFERENCES}

1. Adachi, O., T. Kawai, K. Takeda, M. Matsumoto, H. Tsutsui, M. Sakagami, K. Nakanishi, and S. Akira. 1998. Targeted disruption of the MyD88 gene results in loss of IL-1- and IL-18-mediated function. Immunity 9:143-150.

2. Ahmad-Nejad, P., H. Hacker, M. Rutz, S. Bauer, R. M. Vabulas, and H. Wagner. 2002. Bacterial CpG-DNA and lipopolysaccharides activate Tolllike receptors at distinct cellular compartments. Eur. J. Immunol. 32:19581968.

3. Akira, S. 2003. Toll-like receptor signaling. J. Biol. Chem. 278:3810538108.

4. Alexopoulou, L., A. C. Holt, R. Medzhitov, and R. A. Flavell. 2001. Recognition of double-stranded RNA and activation of NF-kappaB by Toll-like receptor 3. Nature 413:732-738.

5. Aliprantis, A. O., R. B. Yang, D. S. Weiss, P. Godowski, and A. Zychlinsky. 2000. The apoptotic signaling pathway activated by Toll-like receptor- 2 . EMBO J. 19:3325-3336.

6. Arbibe, L., J. P. Mira, N. Teusch, L. Kline, M. Guha, N. Mackman, P. J. Godowski, R. J. Ulevitch, and U. G. Knaus. 2000. Toll-like receptor 2-mediated NF-kappa B activation requires a Rac1-dependent pathway. Nat. Immunol. 1:533-540.

7. Asselin-Paturel, C., A. Boonstra, M. Dalod, I. Durand, N. Yessaad, C. Dezutter-Dambuyant, A. Vicari, A. O'Garra, C. Biron, F. Briere, and G. Trinchieri. 2001. Mouse type I IFN-producing cells are immature APCs with plasmacytoid morphology. Nat. Immunol. 2:1144-1150.

8. Bauer, S., C. J. Kirschning, H. Hacker, V. Redecke, S. Hausmann, S. Akira, H. Wagner, and G. B. Lipford. 2001. Human TLR9 confers responsiveness to bacterial DNA via species-specific CpG motif recognition. Proc. Natl. Acad. Sci. USA 98:9237-9242.

9. Bieback, K., E. Lien, I. M. Klagge, E. Avota, J. Schneider-Schaulies, W. P. Duprex, H. Wagner, C. J. Kirschning, V. Ter Meulen, and S. SchneiderSchaulies. 2002. Hemagglutinin protein of wild-type measles virus activates Toll-like receptor 2 signaling. J. Virol. 76:8729-8736.

10. Bin, L. H., L. G. Xu, and H. B. Shu. 2003. TIRP, a novel Toll/interleukin-1 receptor (TIR) domain-containing adapter protein involved in TIR signaling. J. Biol. Chem. 278:24526-24532.

11. Boehme, K. W., J. Singh, S. T. Perry, and T. Compton. 2004. Human cytomegalovirus elicits a coordinated cellular antiviral response via envelope glycoprotein B. J. Virol. 78:1202-1211.

11a.Bowie, A., E. Kiss-Toth, V. A. Symons, G. L. Smith, S. K. Dower, and L. A. J. O'Neill. 2000. A46R and AS2R from vaccinia virus are antagonists of host IL-1 and toll-like receptor signaling. Proc. Natl. Acad. Sci. USA 97: 10162-10167.

12. Boyle, K. A., R. L. Pietropaolo, and T. Compton. 1999. Engagement of the cellular receptor for glycoprotein B of human cytomegalovirus activates the interferon-responsive pathway. Mol. Cell. Biol. 19:3607-3613.

13. Burns, K., F. Martinon, C. Esslinger, H. Pahl, P. Schneider, J. L. Bodmer, F. Di Marco, L. French, and J. Tschopp. 1998. MyD88, an adapter protein involved in interleukin-1 signaling. J. Biol. Chem. 273:12203-12209.

14. Burzyn, D., J. C. Rassa, D. Kim, I. Nepomnaschy, S. R. Ross, and I. Piazzon. 2004. Toll-like receptor 4-dependent activation of dendritic cells by a retrovirus. J. Virol. 78:576-584.

15. Cella, M., D. Jarrossay, F. Facchetti, O. Alebardi, H. Nakajima, A. Lanzavecchia, and M. Colonna. 1999. Plasmacytoid monocytes migrate to inflamed lymph nodes and produce large amounts of type I interferon. Nat. Med. 5:919-923.

16. Chin, K. C., and P. Cresswell. 2001. Viperin (cig5), an IFN-inducible antiviral protein directly induced by human cytomegalovirus. Proc. Natl. Acad. Sci. USA 98:15125-15130.

17. Chuang, T., and R. J. Ulevitch. 2001. Identification of hTLR10: a novel human Toll-like receptor preferentially expressed in immune cells. Biochim. Biophys. Acta 1518:157-161.

18. Chuang, T. H., and R. J. Ulevitch. 2000. Cloning and characterization of a sub-family of human toll-like receptors: hTLR7, hTLR8 and hTLR9. Eur. Cytokine Netw. 11:372-378.

19. Compton, T., E. A. Kurt-Jones, K. W. Boehme, J. Belko, E. Latz, D. T. Golenbock, and R. W. Finberg. 2003. Human cytomegalovirus activates inflammatory cytokine responses via CD14 and Toll-like receptor 2. J. Virol. 77:4588-4596.

20. Dalod, M., T. Hamilton, R. Salomon, T. P. Salazar-Mather, S. C. Henry, J. D. Hamilton, and C. A. Biron. 2003. Dendritic cell responses to early murine cytomegalovirus infection: subset functional specialization and differential regulation by interferon alpha/beta. J. Exp. Med. 197:885-898.

21. Dalod, M., T. P. Salazar-Mather, L. Malmgaard, C. Lewis, C. AsselinPaturel, F. Briere, G. Trinchieri, and C. A. Biron. 2002. Interferon alpha/ beta and interleukin 12 responses to viral infections: pathways regulating dendritic cell cytokine expression in vivo. J. Exp. Med. 195:517-528.

22. Diebold, S. S., T. Kaisho, H. Hemmi, S. Akira, and E. S. C. Reis. 2004. Innate antiviral responses by means of TLR7-mediated recognition of single-stranded RNA. Science 303:1529-1531.

23. Du, X., A. Poltorak, Y. Wei, and B. Beutler. 2000. Three novel mammalian 
toll-like receptors: gene structure, expression, and evolution. Eur. Cytokine Netw. 11:362-371.

24. Feldman, S. B., M. Ferraro, H. M. Zheng, N. Patel, S. Gould-Fogerite, and P. Fitzgerald-Bocarsly. 1994. Viral induction of low frequency interferonalpha producing cells. Virology 204:1-7.

25. Fitzgerald, K. A., E. M. Palsson-McDermott, A. G. Bowie, C. A. Jefferies, A. S. Mansell, G. Brady, E. Brint, A. Dunne, P. Gray, M. T. Harte, D. McMurray, D. E. Smith, J. E. Sims, T. A. Bird, and L. A. O'Neill. 2001. Ma (MyD88-adapter-like) is required for Toll-like receptor-4 signal transduction. Nature 413:78-83.

26. Fitzgerald, K. A., D. C. Rowe, B. J. Barnes, D. R. Caffrey, A. Visintin, E. Latz, B. Monks, P. M. Pitha, and D. T. Golenbock. 2003. LPS-TLR4 signaling to IRF-3/7 and NF-kappaB involves the toll adapters TRAM and TRIF. J. Exp. Med. 198:1043-1055.

27. Fonteneau, J. F., M. Gilliet, M. Larsson, I. Dasilva, C. Munz, Y. J. Liu, and N. Bhardwaj. 2003. Activation of influenza virus-specific CD4+ and CD8+ T cells: a new role for plasmacytoid dendritic cells in adaptive immunity. Blood 101:3520-3526.

28. Gordon, S. 2002. Pattern recognition receptors: doubling up for the innate immune response. Cell 111:927-930.

29. Hacker, H., H. Mischak, T. Miethke, S. Liptay, R. Schmid, T. Sparwasser, K. Heeg, G. B. Lipford, and H. Wagner. 1998. CpG-DNA-specific activation of antigen-presenting cells requires stress kinase activity and is preceded by non-specific endocytosis and endosomal maturation. EMBO J. 17:62306240.

29a.Harte, M. T., I. R. Haga, G. Maloney, P. Gray, P. C. Reading, N. W. Bartlett, G. L. Smith, A. Bowie, and L. A. J. O'Neill. 2003. The poxvirus protein AS2R targets toll-like receptor signaling complexes to suppress host defense. J. Exp. Med. 197:343-351.

30. Haynes, L. M., D. D. Moore, E. A. Kurt-Jones, R. W. Finberg, L. J. Anderson, and R. A. Tripp. 2001. Involvement of Toll-like receptor 4 in innate immunity to respiratory syncytial virus. J. Virol. 75:10730-10737.

31. Haziot, A., S. Chen, E. Ferrero, M. G. Low, R. Silber, and S. M. Goyert. 1988. The monocyte differentiation antigen, CD14, is anchored to the cell membrane by a phosphatidylinositol linkage. J. Immunol. 141:547-552.

32. Heil, F., P. Ahmad-Nejad, H. Hemmi, H. Hochrein, F. Ampenberger, T. Gellert, H. Dietrich, G. Lipford, K. Takeda, S. Akira, H. Wagner, and S. Bauer. 2003. The Toll-like receptor 7 (TLR7)-specific stimulus loxoribine uncovers a strong relationship within the TLR7, 8 and 9 subfamily. Eur. J. Immunol. 33:2987-2997.

33. Heil, F., H. Hemmi, H. Hochrein, F. Ampenberger, C. Kirschning, S. Akira, G. Lipford, H. Wagner, and S. Bauer. 2004. Species-specific recognition of single-stranded RNA via toll-like receptor 7 and 8. Science 303:1526-1529.

34. Hemmi, H., T. Kaisho, O. Takeuchi, S. Sato, H. Sanjo, K. Hoshino, T. Horiuchi, H. Tomizawa, K. Takeda, and S. Akira. 2002. Small anti-viral compounds activate immune cells via the TLR7 MyD88-dependent signaling pathway. Nat. Immunol. 3:196-200.

35. Hemmi, H., O. Takeuchi, T. Kawai, T. Kaisho, S. Sato, H. Sanjo, M Matsumoto, K. Hoshino, H. Wagner, K. Takeda, and S. Akira. 2000. A Toll-like receptor recognizes bacterial DNA. Nature 408:740-745.

36. Hertzog, P. J., L. A. O'Neill, and J. A. Hamilton. 2003. The interferon in TLR signaling: more than just antiviral. Trends Immunol. 24:534-539.

37. Hoebe, K., E. M. Janssen, S. O. Kim, L. Alexopoulou, R. A. Flavell, J. Han, and B. Beutler. 2003. Upregulation of costimulatory molecules induced by lipopolysaccharide and double-stranded RNA occurs by Trif-dependent and Trif-independent pathways. Nat. Immunol. 4:1223-1229.

38. Horng, T., G. M. Barton, and R. Medzhitov. 2001. TIRAP: an adapter molecule in the Toll signaling pathway. Nat. Immunol. 2:835-841.

39. Hornung, V., S. Rothenfusser, S. Britsch, A. Krug, B. Jahrsdorfer, T. Giese, S. Endres, and G. Hartmann. 2002. Quantitative expression of Toll-like receptor 1-10 mRNA in cellular subsets of human peripheral blood mononuclear cells and sensitivity to $\mathrm{CpG}$ oligodeoxynucleotides. J. Immunol. 168:4531-4537.

40. Into, T., K. Kiura, M. Yasuda, H. Kataoka, N. Inoue, A. Hasebe, K. Takeda, S. Akira, and K. I. Shibata. 2004. Stimulation of human Toll-like receptor (TLR) 2 and TLR6 with membrane lipoproteins of Mycoplasma fermentans induces apoptotic cell death after NF-кB activation. Cell. Microbiol. 6:187199.

41. Jude, B. A., Y. Pobezinskaya, J. Bishop, S. Parke, R. M. Medzhitov, A. V. Chervonsky, and T. V. Golovkina. 2003. Subversion of the innate immune system by a retrovirus. Nat. Immunol. 4:573-578

42. Jurk, M., F. Heil, J. Vollmer, C. Schetter, A. M. Krieg, H. Wagner, G. Lipford, and S. Bauer. 2002. Human TLR7 or TLR8 independently confer responsiveness to the antiviral compound R-848. Nat. Immunol. 3:499.

43. Kaisho, T., and S. Akira. 2001. Dendritic-cell function in Toll-like receptorand MyD88-knockout mice. Trends Immunol. 22:78-83.

44. Kaisho, T., K. Hoshino, T. Iwabe, O. Takeuchi, T. Yasui, and S. Akira 2002. Endotoxin can induce MyD88-deficient dendritic cells to support $\mathrm{T}(\mathrm{h}) 2$ cell differentiation. Int. Immunol. 14:695-700.

45. Kaisho, T., O. Takeuchi, T. Kawai, K. Hoshino, and S. Akira. 2001. Endotoxin-induced maturation of MyD88-deficient dendritic cells. J. Immunol. 166:5688-5694.
46. Kawai, T., O. Adachi, T. Ogawa, K. Takeda, and S. Akira. 1999. Unresponsiveness of MyD88-deficient mice to endotoxin. Immunity 11:115-122.

47. Kawai, T., O. Takeuchi, T. Fujita, J. Inoue, P. F. Muhlradt, S. Sato, K Hoshino, and S. Akira. 2001. Lipopolysaccharide stimulates the MyD88independent pathway and results in activation of IFN-regulatory factor 3 and the expression of a subset of lipopolysaccharide-inducible genes. J. Immunol. 167:5887-5894.

48. Krug, A., G. D. Luker, W. Barchet, D. A. Leib, S. Akira, and M. Colonna. 2004. Herpes simplex virus type 1 activates murine natural interferonproducing cells through toll-like receptor 9. Blood 103:1433-1437.

49. Kurt-Jones, E. A., M. Chan, S. Zhou, J. Wang, G. Reed, R. Bronson, M. M. Arnold, D. M. Knipe, and R. W. Finberg. 2004. Herpes simplex virus 1 interaction with Toll-like receptor 2 contributes to lethal encephalitis. Proc. Natl. Acad. Sci. USA 101:1315-1320.

50. Kurt-Jones, E. A., L. Popova, L. Kwinn, L. M. Haynes, L. P. Jones, R. A. Tripp, E. E. Walsh, M. W. Freeman, D. T. Golenbock, L. J. Anderson, and R. W. Finberg. 2000. Pattern recognition receptors TLR4 and CD14 mediate response to respiratory syncytial virus. Nat. Immunol. 1:398-401.

51. Lee, J., T. H. Chuang, V. Redecke, L. She, P. M. Pitha, D. A. Carson, E. Raz and H. B. Cottam. 2003. Molecular basis for the immunostimulatory activity of guanine nucleoside analogs: activation of Toll-like receptor 7. Proc. Natl. Acad. Sci. USA 100:6646-6651.

52. Lemaitre, B., E. Nicolas, L. Michaut, J. M. Reichhart, and J. A. Hoffmann. 1996. The dorsoventral regulatory gene cassette spatzle/Toll/cactus controls the potent antifungal response in Drosophila adults. Cell 86:973-983.

53. Lord, K. A., B. Hoffman-Liebermann, and D. A. Liebermann. 1990. Nucleotide sequence and expression of a cDNA encoding MyD88, a novel myeloid differentiation primary response gene induced by IL6. Oncogene 5:1095-1097.

54. Lund, J., A. Sato, S. Akira, R. Medzhitov, and A. Iwasaki. 2003. Toll-like receptor 9-mediated recognition of herpes simplex virus-2 by plasmacytoid dendritic cells. J. Exp. Med. 198:513-520.

55. Lund, J. M., L. Alexopoulou, A. Sato, M. Karow, N. C. Adams, N. W. Gale, A. Iwasaki, and R. A. Flavell. 2004. Recognition of single-stranded RNA viruses by Toll-like receptor 7. Proc. Natl. Acad. Sci. USA 101:5598-5603.

56. Matsumoto, M., K. Funami, M. Tanabe, H. Oshiumi, M. Shingai, Y. Seto A. Yamamoto, and T. Seya. 2003. Subcellular localization of Toll-like receptor 3 in human dendritic cells. J. Immunol. 171:3154-3162.

57. Matsumoto, M., S. Kikkawa, M. Kohase, K. Miyake, and T. Seya. 2002 Establishment of a monoclonal antibody against human Toll-like receptor 3 that blocks double-stranded RNA-mediated signaling. Biochem. Biophys. Res. Commun. 293:1364-1369.

58. Medzhitov, R., P. Preston-Hurlburt, and C. A. Janeway, Jr. 1997. A human homologue of the Drosophila Toll protein signals activation of adaptive immunity. Nature 388:394-397.

59. Ojaniemi, M., V. Glumoff, K. Harju, M. Liljeroos, K. Vuori, and M. Hallman. 2003. Phosphatidylinositol 3-kinase is involved in Toll-like receptor 4-mediated cytokine expression in mouse macrophages. Eur. J. Immunol. 33:597-605.

60. O'Neill, L. A. 2003. The role of MyD88-like adapters in Toll-like receptor signal transduction. Biochem. Soc. Trans. 31:643-647.

61. Oshiumi, H., M. Matsumoto, K. Funami, T. Akazawa, and T. Seya. 2003. TICAM-1, an adaptor molecule that participates in Toll-like receptor 3-mediated interferon-beta induction. Nat. Immunol. 4:161-167.

62. Oshiumi, H., M. Sasai, K. Shida, T. Fujita, M. Matsumoto, and T. Seya 2003. TIR-containing adapter molecule (TICAM)-2, a bridging adapter recruiting to toll-like receptor 4 TICAM-1 that induces interferon-beta. J. Biol. Chem. 278:49751-49762.

63. Perussia, B., V. Fanning, and G. Trinchieri. 1985. A leukocyte subset bearing HLA-DR antigens is responsible for in vitro alpha interferon production in response to viruses. Nat. Immun. Cell Growth Regul. 4:120-137.

64. Poltorak, A., X. He, I. Smirnova, M. Y. Liu, C. Van Huffel, X. Du, D. Birdwell, E. Alejos, M. Silva, C. Galanos, M. Freudenberg, P. RicciardiCastagnoli, B. Layton, and B. Beutler. 1998. Defective LPS signaling in $\mathrm{C} 3 \mathrm{H} / \mathrm{HeJ}$ and $\mathrm{C} 57 \mathrm{BL} / 10 \mathrm{ScCr}$ mice: mutations in Tlr4 gene. Science $\mathbf{2 8 2}$ 2085-2088

65. Qureshi, S. T., L. Lariviere, G. Leveque, S. Clermont, K. J. Moore, P. Gros, and D. Malo. 1999. Endotoxin-tolerant mice have mutations in Toll-like receptor 4 (Tlr4). J. Exp. Med. 189:615-625.

66. Rassa, J. C., J. L. Meyers, Y. Zhang, R. Kudaravalli, and S. R. Ross. 2002 Murine retroviruses activate $\mathrm{B}$ cells via interaction with Toll-like receptor 4 . Proc. Natl. Acad. Sci. USA 99:2281-2286.

67. Rock, F. L., G. Hardiman, J. C. Timans, R. A. Kastelein, and J. F. Bazan. 1998. A family of human receptors structurally related to Drosophila Toll. Proc. Natl. Acad. Sci. USA 95:588-593.

68. Ronnblom, L., B. Cederblad, K. Sandberg, and G. V. Alm. 1988. Determination of herpes simplex virus-induced alpha interferon-secreting human blood leucocytes by a filter immuno-plaque assay. Scand. J. Immunol. 27:165-170

69. Schumann, R. R., S. R. Leong, G. W. Flaggs, P. W. Gray, S. D. Wright, J. C. Mathison, P. S. Tobias, and R. J. Ulevitch. 1990. Structure and function of lipopolysaccharide binding protein. Science 249:1429-1431. 
70. Siegal, F. P., N. Kadowaki, M. Shodell, P. A. Fitzgerald-Bocarsly, K. Shah, S. Ho, S. Antonenko, and Y. J. Liu. 1999. The nature of the principal type 1 interferon-producing cells in human blood. Science 284:1835-1837.

71. Simmen, K. A., J. Singh, B. G. Luukkonen, M. Lopper, A. Bittner, N. E. Miller, M. R. Jackson, T. Compton, and K. Fruh. 2001. Global modulation of cellular transcription by human cytomegalovirus is initiated by viral glycoprotein B. Proc. Natl. Acad. Sci. USA 98:7140-7145.

72. St. Johnston, D., and C. Nusslein-Volhard. 1992. The origin of pattern and polarity in the Drosophila embryo. Cell 68:201-219.

73. Tabeta, K., P. Georgel, E. Janssen, X. Du, K. Hoebe, K. Crozat, S. Mudd, L. Shamel, S. Sovath, J. Goode, L. Alexopoulou, R. A. Flavell, and B. Beutler. 2004. Toll-like receptors 9 and 3 as essential components of innate immune defense against mouse cytomegalovirus infection. Proc. Natl. Acad. Sci. USA 101:3516-3521.

74. Takeda, K., T. Kaisho, and S. Akira. 2003. Toll-like receptors. Annu. Rev. Immunol. 21:335-376.

75. Takeuchi, O., T. Kawai, H. Sanjo, N. G. Copeland, D. J. Gilbert, N. A. Jenkins, K. Takeda, and S. Akira. 1999. TLR6: a novel member of an expanding toll-like receptor family. Gene 231:59-65.

76. Wright, S. D., R. A. Ramos, P. S. Tobias, R. J. Ulevitch, and J. C. Mathison. 1990. CD14, a receptor for complexes of lipopolysaccharide (LPS) and LPS binding protein. Science 249:1431-1433.

77. Yamamoto, M., S. Sato, H. Hemmi, K. Hoshino, T. Kaisho, H. Sanjo, O.
Takeuchi, M. Sugiyama, M. Okabe, K. Takeda, and S. Akira. 2003. Role of adaptor TRIF in the MyD88-independent toll-like receptor signaling pathway. Science 301:640-643.

78. Yamamoto, M., S. Sato, H. Hemmi, S. Uematsu, K. Hoshino, T. Kaisho, O. Takeuchi, K. Takeda, and S. Akira. 2003. TRAM is specifically involved in the Toll-like receptor 4-mediated MyD88-independent signaling pathway. Nat. Immunol. 4:1144-1150.

79. Yamamoto, M., S. Sato, K. Mori, K. Hoshino, O. Takeuchi, K. Takeda, and S. Akira. 2002. Cutting edge: a novel Toll/IL-1 receptor domain-containing adapter that preferentially activates the IFN-beta promoter in the Toll-like receptor signaling. J. Immunol. 169:6668-6672.

80. Yurochko, A. D., E. S. Hwang, L. Rasmussen, S. Keay, L. Pereira, and E. S. Huang. 1997. The human cytomegalovirus UL55 (gB) and UL75 (gH) glycoprotein ligands initiate the rapid activation of Sp1 and NF- $\mathrm{B}$ during infection. J. Virol. 71:5051-5059.

81. Zarember, K. A., and P. J. Godowski. 2002. Tissue expression of human Toll-like receptors and differential regulation of Toll-like receptor mRNAs in leukocytes in response to microbes, their products, and cytokines. J. Immunol. 168:554-561.

82. Zhang, D., G. Zhang, M. S. Hayden, M. B. Greenblatt, C. Bussey, R. A. Flavell, and S. Ghosh. 2004. A toll-like receptor that prevents infection by uropathogenic bacteria. Science 303:1522-1526. 